\title{
Biotransformation of Chemicals at the Water-Sediment Interface-Toward a Robust Simulation Study Setup
}

\author{
Carolin Seller, Birge D. Özel Duygan, Mark Honti, and Kathrin Fenner*
}

Cite This: ACS Environ. Au 2021, 1, 46-57

Read Online

ABSTRACT: Studying aquatic biotransformation of chemicals in laboratory experiments, i.e., OECD 308 and OECD 309 studies, is required by international regulatory frameworks to prevent the release of persistent chemicals into natural water bodies. Here, we aimed to address several previously described shortcomings of OECD 308/309 studies regarding their variable outcomes and questionable environmental relevance by broadly testing and characterizing a modified biotransformation test system in which an aerated water column covers a thin sediment layer. Compared to standard OECD 308/309 studies, the modified system showed little inter-replicate variability, improved observability of biotransformation, and consistency with first-order biotransformation
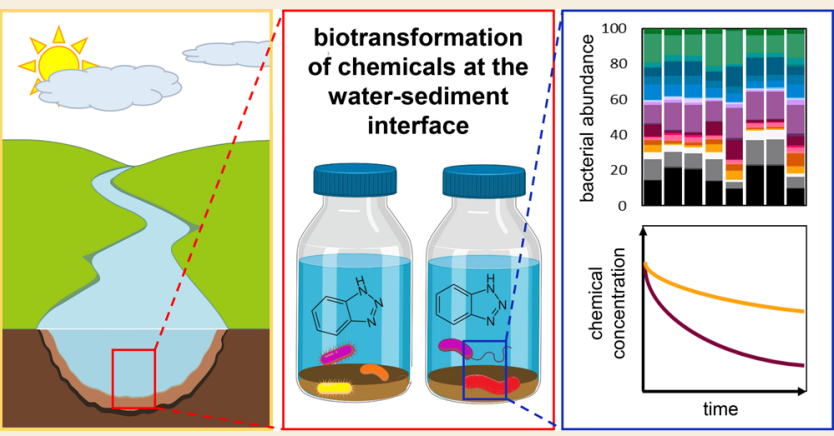

kinetics for the majority of 43 test compounds, including pharmaceuticals, pesticides, and artificial sweeteners. To elucidate the factors underlying the decreased inter-replicate variability compared to OECD 309 outcomes, we used multidimensional flow cytometry data and a machine learning-based cell type assignment pipeline to study cell densities and cell type diversities in the sediment and water compartments. Our here presented data on cell type composition in both water and sediment allows, for the first time, to study the behavior of microbial test communities throughout different biotransformation simulation studies. We found that sediment-associated microbial communities were generally more stable throughout the experiments and exhibited higher cell type diversity than the water column-associated communities. Consistently, our data indicate that aquatic biotransformation of chemicals can be most robustly studied in test systems providing a sufficient amount of sediment-borne biomass. While these findings favor OECD 308-type systems over OECD 309-type systems to study biotransformation at the water-sediment interface, our results suggest that the former should be modified toward lower sediment-water ratios to improve observability and interpretability of biotransformation.

KEYWORDS: biotransformation, micropollutants, chemical persistence, water-sediment systems, phenotypic microbial community composition, cell type diversity, OECD 308/309 studies

\section{INTRODUCTION}

Persistent chemicals, i.e., chemicals recalcitrant to biotic and abiotic transformation, are of concern when entering the aquatic environment as they can distribute widely, reach high concentrations, and induce environmental exposure that is difficult to control and reverse. ${ }^{1,2}$ Persistence assessment of organic chemicals is therefore a key piece in many international regulatory frameworks. ${ }^{1-3}$ Yet, professionals in academia, government, and industry involved in the persistence assessment of chemicals have been raising concerns regarding the robustness and reliability of today's standard procedures to assess a chemical's potential for biotransformation in the aquatic environment. ${ }^{4-8}$

An integral part of persistence assessment for chemicals entering the aquatic environment is the performance of laboratory studies described in the OECD 308 and OECD 309 guidelines, which aim to simulate a chemical's biotransformation in aquatic sediment and in the pelagic water body, respectively. ${ }^{9,10}$ Dissipation half-lives $\left(\mathrm{DT}_{50}\right)$ obtained from those studies can then be compared against persistence criteria defined in regulatory frameworks, e.g., the REACH regulation of the European Union. ${ }^{2,3}$ Besides the targeted biotransformation, compound dissipation from such test systems is also influenced by abiotic transformation and phase transfer processes. As a consequence, study outcomes depend on numerous parameters including system geometry, sediment properties, $\mathrm{pH}$, temperature, and composition and activity of the microbial community present in the test system. ${ }^{11-13} \mathrm{DT}_{50}$ values are therefore highly variable; e.g.,

Received: April 16, 2021

Published: July 13, 2021 
values obtained from different biotransformation simulation studies can differ by 2-3 orders of magnitude for the same compound. ${ }^{2,5,13,14}$ While interstudy variabilities in $\mathrm{DT}_{50}$ may be considered to represent a spectrum of differing conditions in the aquatic environment, intrastudy variabilities, previously observed in OECD 309-type studies, ${ }^{5}$ further challenge the approach of evaluating a chemical's persistence by comparing laboratory-derived $\mathrm{DT}_{50}$ to predefined persistence cutoff values.

Divergent outcomes of OECD 309 studies, which are performed in natural water (pelagic test) or in water amended with some suspended sediment to a concentration of $\leq 1 \mathrm{~g}$ solids $\mathrm{L}^{-1}$ (suspension test), ${ }^{10}$ may result from vaguely standardized test conditions. ${ }^{15}$ Furthermore, OECD 309 tests are deemed valid when the examined water contains a cell concentration of minimally $10^{3}-10^{4}$ cells $\mathrm{mL}^{-1}$, ${ }^{10}$ even though bacterial cell densities measured in natural freshwater bodies are typically higher and range from $10^{4}$ to $10^{7}$ cells $\mathrm{mL}^{-1} .^{16-19}$ This difference in cell densities may be reflected by the low rates of biotransformation commonly observed in OECD 309 systems ${ }^{15}$ and questions the study's environmental relevance regarding the assessment of a chemical's potential for biotransformation if indeed performed at minimal allowed cell concentrations.

OECD 308 studies are carried out under stagnant conditions with a $2-3 \mathrm{~cm}$ thick sediment layer covered by a shallow water column to a sediment-water ratio of $1: 3$ or $1: 4(\mathrm{v} / \mathrm{v}) .^{9}$ The increased amount of sediment-borne biomass added to experimental vessels of OECD 308 studies may clearly result in higher cell densities compared to OECD 309 studies. Nevertheless, OECD 308 study outcomes are often difficult to interpret as compound mass distribution can excessively shift into the sediment layer where mixed redox conditions prevail, making $\mathrm{DT}_{50}$ strongly dependent on sediment properties. $^{8,12,20-22}$ Considering the aim of simulation studies to target transformation rather than phase transfer processes, Shrestha et al. ${ }^{8}$ addressed shortcomings of standard OECD 308 studies by introducing a modified test system in which a fully aerated water column covers a thin sediment layer to a sediment-water ratio of $1: 10(\mathrm{v} / \mathrm{v})$. While the results of these modified OECD 308-type experiments suggested that contact of the test compounds with the sediment was indeed more likely to lead to biotransformation than to (irreversible) sorption, ${ }^{8}$ the study was limited to only four test compounds. Hence, the modified experimental design requires further evaluation.

Another potential shortcoming of biotransformation simulation studies is that the OECD 308/309 guidelines do not require any analysis of the composition or diversity of the microbial communities present in the test systems, ${ }^{9,10}$ even though several studies have identified positive correlations between cell density and/or diversity of microbial communities and their capacity for biotransformation of chemicals. ${ }^{5,23-26}$ However, to the best of our knowledge, the effect of differing microbial biomass and community composition on a chemical's biotransformation has not yet been studied across different biotransformation simulation studies. Hence, linking the occurrence of inter- and intrastudy variabilities in compound dissipation to varying cell density, composition, and diversity of different microbial communities in the test systems is currently neglected in the context of regulatory persistence assessment.
Commonly applied methods to investigate composition and diversity of a microbial community are based on DNA or RNA sequencing and emphasize taxonomic or functional gene diversity. ${ }^{27,28}$ Yet, such approaches are still relatively slow and laborious, ${ }^{29,30}$ which is a disadvantage in fields requiring analysis of a great number of samples or rapid analysis of community dynamics. In contrast to sequencing platforms, advances in high-throughput optic-based flow cytometry (FCM) measurements enable sensitive real-time sample analysis and interpretation. Different FCM data processing pipelines allow simultaneous absolute quantification of cells, identification of different cell types, and recognition of community diversity based on the cells' multidimensional FCM fingerprints. ${ }^{27,28,31,32}$ Hence, FCM measurements and appropriate data analysis tools could be used to easily and rapidly assess phenotypic differences and dynamic changes within different microbial test communities.

Against this scientific background, the goal of this study was twofold: First, we aimed to further develop and validate the concept of a modified OECD 308-type test system that would allow to robustly study aquatic biotransformation of a set of structurally diverse chemicals. To this end, we conducted modified OECD 308-type studies with a set of 43 compounds (i.e., pharmaceuticals, pesticides, and artificial sweeteners) and compared those study outcomes, i.e., $\mathrm{DT}_{50}$ values, with those obtained from standard OECD 308 studies and OECD 309type suspension tests employing sediment concentrations within and beyond regulatory standards. Second, we aimed to elucidate the influence of cell density, cell type composition, and diversity of microbial communities on outcomes of biotransformation simulation studies to further explain occurrence of intra- and interstudy variabilities in compound removal. FCM data from modified OECD 308-type studies and OECD 309 suspension tests were analyzed by deploying a machine-learning cell type assignment pipeline (CellCognize $)^{28}$ to monitor morphological community composition and diversity. Alongside those objectives, we gathered valuable information on the biotransformation and sorption behavior of a broad range of environmentally relevant chemicals that are frequently detected in wastewater treatment plant (WWTP) effluents, surface water bodies, and even ground- and drinking water resources. $^{33-39}$

\section{MATERIALS AND METHODS}

\section{Test Compounds}

Test compounds were chosen based on the selection of Seller et al., ${ }^{5}$ including 24 pharmaceuticals, 15 pesticides, 3 artificial sweeteners, and 1 industrial chemical, and cover a broad range of different transformation and sorption behavior. A list of test compounds including name abbrevations is provided in Table SI1.

\section{Biotransformation Experiments}

Water and sediment for biotransformation experiments were sampled from the agriculture- and WWTP effluent-impacted river Rhine (Mumpf, Switzerland) in March 2019 and from the pristine Cressbrook Mill Pond in August 2019 (CMP, Derbyshire, UK). In compliance with the OECD 308 guideline, the two sampling sites were chosen to strongly differ in texture and total organic carbon (TOC) content of the sediment. ${ }^{9}$ The coarse-textured sediment from the Rhine (i.e., $73 \%$ sand, $20 \%$ silt, $7 \%$ clay) had a TOC content of $0.7 \%$, while the much finer sediment of CMP (i.e., $45 \%$ sand, $49 \%$ silt, $5 \%$ clay) had a TOC content of $10 \%$. Details about the environmental sampling are provided in Table SI2. Water and sediment samples were cooled on ice during transport to the laboratory (i.e., $2 \mathrm{~h}$ and 4 days in 
case of Rhine and CMP samples, respectively) and then directly filled into experimental containers to allow acclimation to test conditions.

Biotransformation experiments with environmental samples from CMP and Rhine were conducted in $1 \mathrm{~L}$ glass bottles (i.e., $\varnothing=10 \mathrm{~cm}$ ) at a sediment-water ratio of $1: 10(\mathrm{v} / \mathrm{v})$; hence, a $1 \mathrm{~cm}$ thick sediment layer, i.e., 30 and $100 \mathrm{~g}_{\text {dry weight }}$ of $\mathrm{CMP}$ and Rhine sediment, respectively, was covered by $750 \mathrm{~mL}$ of water. The water column was aerated with wet air flowing through a syringe ending $1.5 \mathrm{~cm}$ above the sediment surface, resulting in a continuous stream of air bubbles, which mixed the water column but did not visibly disturb the sediment's upper layer. A total of 18 experimental replicates was set up and an acclimation period of 7 days was applied to reach stable $\mathrm{pH}$ and $\mathrm{O}_{2}$ concentrations in the water phase before spiking a mix of test compounds dissolved in ethanol into the experimental vessels to individual concentrations of $1 \mu \mathrm{g} \mathrm{L}^{-1}$, resulting in a solvent addition of $0.04 \%(\mathrm{v} / \mathrm{v})$. Biotransformation experiments were carried out at room temperature $\left(22 \pm 2{ }^{\circ} \mathrm{C}\right)$ in the dark. To determine chemical concentrations in the sediment and water phase, two replicates were sacrificed at nine sampling time points throughout $>54$ days. Aliquots of $1.5 \mathrm{~mL}$ were taken from the water phase of the respective sacrificed replicates and centrifuged at $20000 \mathrm{~g}$ for $10 \mathrm{~min}$, and the supernatant was transferred into HPLC vials where a mix of internal standards (ISTD) was added at a concentration of $500 \mathrm{ng} \mathrm{L}^{-1}$ to account for losses during chemical analysis.

To determine compound concentrations in the sediment layer, the supernatant water was decanted from the experimental vessels and the remaining bulk sediment was homogenized by manual stirring. Sediment samples were then extracted following methods outlined by Loeffler et al. $^{40}$ and Chiaia-Hernande et al. ${ }^{41}$ Briefly, sediment samples were lyophilized and aliquots of 6 and $2 \mathrm{~g}$ of dry Rhine and CMP sediment, respectively, were homogenized with $0.5 \mathrm{~g}$ diatomaceous earth and transferred into $11 \mathrm{~mL}$ stainless-steel cells of an accelerated solvent extractor ASE 350 unit from Dionex, which were equipped with glass fiber and cellulose filters at the bottom. A mixture of nanopure water, methanol, and acetone $(50: 25: 25 \mathrm{v} / \mathrm{v} / \mathrm{v})$ was used as extraction solvent for pressurized liquid extraction (PLE) during two extraction cycles of $5 \mathrm{~min}$, each at $80{ }^{\circ} \mathrm{C}$ and 1500 psi. PLE extracts were evaporated to $1 \mathrm{~mL}$ using a Synocore Polyvap (Büchi, Switzerland). Remaining extracts were centrifuged at $20000 \mathrm{~g}$ for 15 $\mathrm{min}$, and $0.5 \mathrm{~mL}$ of supernatant were transferred to HPLC vials and amended with the ISTD mix to a concentration of $1 \mu \mathrm{g} \mathrm{L}^{-1}$. Absolute compound recoveries after extraction and evaporation were determined by spiking several portions of Rhine and CMP sediment with known amounts of test substances $24 \mathrm{~h}$ prior to extraction. Extraction recoveries are provided in Table SI3.

Abiotic control experiments were set up in duplicates alongside the respective biotransformation experiments to distinguish compound removal via biotransformation from phase transfer processes in experimental vessels. Water and sediment were sterilized by two times autoclaving (each cycle: $120^{\circ} \mathrm{C}$ for $20 \mathrm{~min}$ ); besides sterilization, the experimental setup of abiotic controls was identical to the setup of biotransformation experiments. To identify compound removal via abiotic hydrolysis, test compounds were additionally spiked into experimental vessels containing sterilized water only. As previous studies reported resumed bioactivity in autoclaved samples after extended time periods, ${ }^{13}$ abiotic experiments were conducted for $<20$ days to ensure maintenance of sterile conditions. Compound concentrations in the abiotic control experiments were determined in the water phase only by taking several subsamples from the respective experimental duplicates at various time points (SI2.1).

All samples, i.e., water phase samples and sediment extracts, were analyzed with the same analytical method using an Agilent 6495C Triple Quad mass spectrometer coupled to an Agilent HPLC 1290 (binary pump) system. The analytical method and data evaluation procedures, previously described by Seller et al., ${ }^{5}$ are summarized in SI1.4.

In addition to following the fate of chemicals over the time course of the experiments, we further monitored abundance and phenotypic characteristics of the microbial communities in the sediment and water phase of each experimental vessel by means of FCM. Details on sample preparation, which was consistent with methods outlined by Seller et al., 5 are provided in SI1.6. Prior to FCM analysis on an Accuri C6 flow cytometer (BD, Belgium), microbial samples were stained with SYBR Green I nucleic acid gel stain (Invitrogen AG, Basel, Switzerland) diluted in $10 \mathrm{mM}$ Tris buffer $(\mathrm{pH}=8)$. Green and red fluorescence was measured at $533 \pm 30 \mathrm{~nm}$ (FL1-H channel) and $>670 \mathrm{~nm}$ (FL3-H channel) and bacterial abundance was determined by enumeration of signals collected on the combined FL1/FL3 density plot using the BD Accuri C6 Analysis Software 1.0.264.21. Further, seven FCM parameters (i.e., FITC-A, FITC-H, FSC-A, FSC$\mathrm{H}$, SSC-A, SSC-H, and Width) were recorded for each cell detected in the respective water and sediment samples for phenotypic cell type classification and cell type diversity analysis as described thereinafter.

\section{Data from Standard OECD 308 Studies and OECD 309-Type Suspension Tests}

Transformation kinetics of selected test compounds in modified OECD 308-type studies were compared to compound behavior in other studies relevant for assessing a chemical's persistence in the aquatic environment. For a subset of 19 compounds (i.e., 5 pharmaceuticals and 14 pesticides, Table SI1), the German Environment Agency kindly provided regulatory dossiers from standard OECD 308 experiments conducted at sediment-water ratios of $1: 3$ or $1: 4(\mathrm{v} / \mathrm{v})$ employing water and sediment sampled from various freshwater bodies. Regulatory dossiers contained raw data describing the parent compounds residue-time series in water and sediment, as well as data on the formation of non-extractable residues (NER) over time.

Further, we compared outcomes of modified OECD 308-type studies to data presented by Seller et al. ${ }^{5}$ describing compound behavior in OECD 309-type suspension tests containing 1 and $10 \mathrm{~g}$ solids $\mathrm{L}^{-1}$. Suspensions are referenced with a code indicating sampling site, i.e., R (Rhine) or CMP, sediment concentration in grams per liter, and sampling season for the Rhine suspensions. The low sediment concentration suspensions are R1-Spring and CMP1, and the high sediment concentration suspensions are R10-Fall and CMP10. It has to be noted that R1-Spring, CMP1, and CMP10 were performed in inocula sampled at the same time as for the modified OECD 308-type studies.

\section{Data Analysis}

Estimation of Lag Phases and Half-Lives. A first-order degradation model considering lag phases was fitted to total parent compound residues in the experimental vessels over time in standard and modified OECD 308-type studies. Model equations provided in SI1.5 match the modified hockey-stick model of the FOCUS guidance on estimating persistence and degradation kinetics from environmental fate studies. ${ }^{42}$ We here defined the total system dissipation half-life $\left(\mathrm{DT}_{50, \mathrm{TS}}\right)$ as the sum of the time interval needed to reach $50 \%$ compound removal from the experimental vessels after onset of degradation plus the length of the lag phase. Modeled transformation kinetics cover biotic and abiotic compound transformation; compounds susceptible to removal via abiotic hydrolysis are listed in Table SI5.

In the case of modified OECD 308-type studies, to account for uncertainties in our data due to potential compound mass losses during sample handling and LC/MS analysis, we only considered compound mass dissipation $>15 \%$ from the test vessels during biotransformation experiments to indicate actual transformation. Therefore, we could only reliably calculate transformation rate constants of $>0.003$ days $^{-1}$ and hence $\mathrm{DT}_{50, \mathrm{TS}}$ of $<230$ days.

In order to enable a comparison between $\mathrm{DT}_{50, \mathrm{TS}}$ values derived from standard and modified OECD 308-type studies, $\mathrm{DT}_{50, \mathrm{TS}}$ from standard studies were calculated via two different approaches. Generally speaking, in the case of standard OECD 308 studies conducted with ${ }^{14} \mathrm{C}$-radiolabeled substances, radioactivity detected in the sediment layer may stem from reversibly sorbed parent compound and transformation products but also include truly irreversibly bound fractions because of compound incorporation into biomass or the formation of covalent bonds. The truly irreversibly bound fraction 
might not necessarily be equal to NER. These are operationally defined by the employed extraction procedure, which is not standardized in current regulatory guidelines. ${ }^{9,40}$ Frequently used batch extraction methods (e.g., $12 \mathrm{~h}$ solvent extraction at room temperature), for instance, are known to provide comparably low extraction efficiencies. ${ }^{40}$

Therefore, to account for uncertainty in extraction efficiencies and to compare to our own modified OECD 308-type studies, in which we only quantified parent compound mass, we calculated $\mathrm{DT}_{50, \mathrm{TS}}$ from standard OECD 308-type studies in two ways, representing two possible extreme assumptions regarding extraction efficiencies. In the more conservative approach, we calculated total parent compound residues in standard OECD 308-type studies as the sum of NER, sediment-extracted and water phase parent compound. This approach is likely to overestimate parent compound $\mathrm{DT}_{50, \mathrm{TS}}$, as NER not only includes non-extracted parent compound mass but also transformation products and truly irreversibly bound fractions. In the second approach, we calculated total parent compound residues in standard OECD 308-type studies as the sum of sediment-extracted and water phase parent compound only. With this second approach, sediment-bound parent compound mass may be underestimated in case of low and/or varying efficiencies of extraction methods applied.

Working with unlabeled compounds in modified OECD 308-type studies did not allow us to monitor the formation of NER. However, PLE treatment of sediment samples can be assumed to have resulted in a much more efficient extraction of parent compound mass compared to standard OECD 308 studies. ${ }^{40}$ We further corrected measured parent compound concentrations in the sediment by dividing the extracted compound mass by the separately determined absolute recovery for each test compound to account for losses during sample treatment.

In the following, $\mathrm{DT}_{50, \mathrm{TS}}$ values derived from our modified studies were compared to both $\mathrm{DT}_{50, \mathrm{TS}}$ values derived from standard studies. It is to note that, while we calculated two types of $\mathrm{DT}_{50, \mathrm{TS}}$ from standard OECD 308 studies to account for differing efficiencies of different sediment extraction methods, we do not further address the question of how to interpret NER in this study.

Microbial Community Cell Type Composition and Diversity. Multidimensional FCM data collected during modified OECD 308type studies and suspension tests presented by Seller et al. ${ }^{5}$ were used to distinct cytometric fingerprints of the different samples by principal component analysis (PCA). While PCA with two components explained $70 \%$ of covariation (Figure SI1), PCA results suggested that differences between samples were not occurring by chance but were driven by significantly differing microbial compositions in the water and sediment compartment, respectively. Therefore, we further analyzed FCM data by deploying the machine-learning cell type assignment pipeline of Özel Duygan et al. ${ }^{28}$ called CellCognize. Briefly, in CellCognize, the seven recorded FCM parameters were considered for classification based on multidimensional resemblance between 32 predefined standard microbeads and strains (Table SI4 and Figure SI2) and unknown cells from the microbial samples. Each cell passing the applied thresholds for each of the seven FCM parameters was $\log 10$ transformed and positioned via anchors. Then, classifier algorithms were used to calculate the probability of similarity of each cell compared to the 32 standard classifiers and cells were attributed to the respective standard classifier yielding highest probability. This classification was then used to assess community cell type composition and its differences between samples and studies. Cell type diversity was determined by calculating Shannon indices.

\section{RESULTS AND DISCUSSION}

\section{Compound Dissipation from Water-Sediment Systems}

Lag Phases and $\mathrm{DT}_{50, \mathrm{TS}}$ in Modified OECD 308-Type Studies. A compilation of parent compound concentrations measured in the water phase and sediment layer of modified OECD 308-type systems together with the fit of the degradation model to the total parent compound concen- trations are shown in Figure SI4. Based on our experimental data, we were able to determine $\mathrm{DT}_{50, \mathrm{Ts}}$ values (including lag phases) for 42 compounds in CMP and/or Rhine experiments (SI2.2), which are shown in Table SI7 together with statistical model parameters. Lag phases $>2$ days were observed for 14 compounds; however, only isoproturon in CMP experiments had a lag phase $>10$ days. $\mathrm{DT}_{50, \mathrm{Ts}}$ range from $\leq 2$ days (e.g., fenoxycarb and atenolol) to $>230$ days (e.g., carbamazepine and citalopram) and are shown in Figure 1.

$\mathrm{DT}_{50, \mathrm{TS}}$ values derived from modified OECD 308-type experiments were rather similar between the Rhine and the CMP study for the majority of test compounds. Both studies identified the same 11 compounds as most rapidly degrading with $\mathrm{DT}_{50, \mathrm{TS}} \leq 10$ days, i.e., fenoxycarb, atenolol, sulfamethoxazole, bezafibrate, trimethoprim, trinexapac-ethyl, valsartan, levetiracetam, iprovalicarb, fenhexamid, and irbesartan. Consistently, those compounds have previously been reported to show rapid biotransformation in studies with activated sludge from WWTPs. ${ }^{43,44}$ In contrast, $\mathrm{DT}_{50 \mathrm{TS}}$ values $>100$ days were determined for the compounds aliskiren, atazanavir, carbamazepine, citalopram, and lamotrigine, for which limited removal was also observed during biological wastewater treatment. ${ }^{44,45}$

Noticeable interstudy differences between $\mathrm{DT}_{50, \mathrm{TS}}$, i.e., coefficients of variation $(\mathrm{CV})>50 \%$ between $\mathrm{DT}_{50, \mathrm{TS}}$ from both studies (Figure SI4), occurred for the three artificial sweeteners acesulfame, cyclamate, and saccharin. $\mathrm{DT}_{50, \mathrm{TS}}$ values of all three sweeteners were roughly one order of magnitude higher in CMP experiments compared to Rhine experiments. In the case of acesulfame, previous research has demonstrated bacterial evolution toward an increased capacity to metabolize the artificial sweetener in WWTPs. ${ }^{46,47}$ Further, it has been shown that WWTP discharge can affect downstream microbial biotransformation capacity in rivers and lakes, such that the sweetener acesulfame, previously considered persistent, can be biotransformed. ${ }^{13,48}$ At the time of environmental sampling for the here conducted biotransformation experiments, none of the target compounds were measured in water samples from CMP; however, several compounds, including the three artificial sweeteners, were quantifiable in water samples from the Rhine at concentrations of up to $250 \mathrm{ng} \mathrm{L}^{-1}$. We hence speculate that pre-exposure of the microbial community sourced from the Rhine to the artificial sweeteners, or export of previously exposed microbes through WWTP effluents into the Rhine, ${ }^{49}$ resulted in an enhanced ability of the Rhine inoculum to biotransform those compounds, explaining the shorter $\mathrm{DT}_{50, \mathrm{Ts}}$. Similarly, isoproturon and metoprolol dissipated significantly faster from experimental vessels of the Rhine study. Both compounds were detected in water samples from the Rhine prior to spiking our test compounds, suggesting that pre-exposure and adaptation of the Rhine inoculum increased its biotransformation capacity also for those two compounds.

On the contrary, the three compounds 5-methylbenzotriazole, bicalutamide, and fexofenadine had shorter $\mathrm{DT}_{50, \mathrm{TS}}$ values in CMP experiments than in Rhine experiments. During biotransformation experiments, we detected a larger amount of those compounds in the sediment layer of the Rhine study than in the sediment layer of the CMP study (Figure SI4), despite their higher affinity toward CMP sediment in abiotic sorption controls (Table SI6), a phenomenon we cannot fully explain based on our data. Yet, longer $\mathrm{DT}_{50, \mathrm{TS}}$ in the biotransformation simulation study with Rhine sediment may 

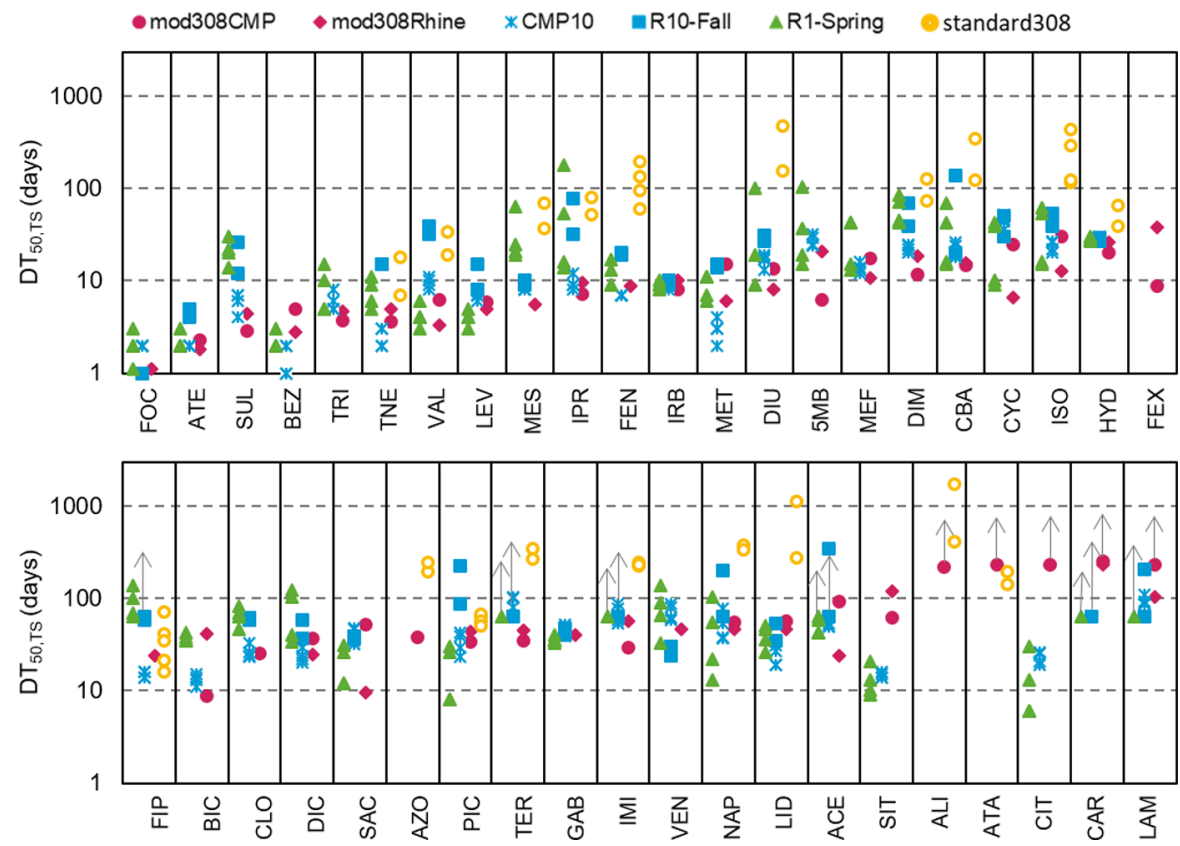

Figure 1. $\mathrm{DT}_{50, \mathrm{TS}}$ of test compounds in OECD 309-type suspension tests containing $1 \mathrm{~g}$ solids $\mathrm{L}^{-1}$ (R1-Spring), suspension tests containing $10 \mathrm{~g}$ solids $L^{-1}$ (CMP10 and R10-Fall), modified OECD 308-type studies employing a sediment-water ratio of 1:10 (v/v) (mod308CMP and mod308Rhine), and in standard OECD 308 studies employing a sediment-water ratio of 1:3 or 1:4 (standard308). In the case of suspension tests, note that different $\mathrm{DT}_{50, \mathrm{TS}}$ values belonging to the same study indicate inter-replicate variabilities. $\mathrm{DT}_{50, \mathrm{TS}}$ values marked with upward pointing arrows cannot be considered as definite values because either $\mathrm{DT}_{50, \mathrm{TS}}$ values were $>230$ days or lag phases exceeded the duration of biotransformation experiments, meaning that the $\mathrm{DT}_{50, \mathrm{TS}}$ values shown are minimal estimates. Standard errors of the degradation model were $<12 \%$.

have resulted from the reduced bioavailability of those compounds.

Comparison of $\mathrm{DT}_{50, \mathrm{Ts}}$ Derived from Standard and Modified OECD 308-Type Systems. The degradation model applied to evaluate modified OECD 308-type studies was also fitted to data extracted from regulatory dossiers describing the fate of 19 test compounds in standard OECD 308 studies (Table SI7). Figure 1 shows $\mathrm{DT}_{50, \mathrm{TS}}$ values calculated when considering extractable compound mass and NER as total parent compound residues, which suggests that $\mathrm{DT}_{50, \mathrm{TS}}$ values are rather conservative estimates. However, observations discussed in the following and conclusions drawn thereof did not change when $\mathrm{DT}_{50, \mathrm{TS}}$ values describing compound behavior in standard OECD 308 studies were calculated based on extractable parent compound mass only (Table SI7).

Generally, $\mathrm{DT}_{50, \mathrm{TS}}$ values derived from standard OECD 308 studies, i.e., systems employing a sediment-water ratio of $1: 3$ or $1: 4(\mathrm{v} / \mathrm{v})$, were rather high, with 12 out of 19 compounds exhibiting $\mathrm{DT}_{50, \mathrm{TS}}>100$ days, exceeding the typical duration of OECD 308 studies. ${ }^{9}$ Compared to standard OECD 308 studies, compound dissipation appeared to be faster in modified OECD 308-type studies, resulting in $\mathrm{DT}_{50, \mathrm{TS}}$ values that were lower by one order of magnitude for the majority of compared compounds. When comparing $\mathrm{DT}_{50, \mathrm{TS}}$ of aliskiren and atazanavir, it has to be noted that $\mathrm{DT}_{50, \mathrm{TS}}$ calculated from modified OECD 308-type studies are subject to rather large uncertainty as the model extrapolated those values far beyond the duration of the experiments; in any case, biotransformation of the two compounds was minimal in both modified and standard biotransformation experiments.

Other than for the majority of compared compounds, $\mathrm{DT}_{50, \mathrm{TS}}$ for hydrochlorothiazide, fipronil, picoxystrobin, and trinexapac-ethyl did not differ as strongly between standard and modified OECD 308-type studies. Since our sterile control experiments indicated that these compounds are susceptible to abiotic hydrolysis (Table SI5), we assume that contribution, or even dominance, of abiotic transformation processes may explain the more similar dissipation kinetics for these compounds in standard and modified OECD 308-type studies.

Interstudy variabilities between different standard OECD 308 studies were significant for 7 out of 19 compounds (i.e., $\mathrm{CV}>50 \%$ between $\mathrm{DT}_{50, \mathrm{TS}}$ values from different studies). Further, when comparing interstudy variabilities of standard OECD 308 studies to interstudy variabilities of modified OECD 308-type studies, CVs between $\mathrm{DT}_{50, \mathrm{Ts}}$ values were higher in standard studies for 8 of the 13 compounds for which at least two $\mathrm{DT}_{50, \mathrm{TS}}$ values were available from both standard and modified OECD 308-tpye studies (Figure SI5). While several parameters (e.g., viability of the microbial test community, oxygen saturation, or $\mathrm{pH}$ ) can influence the outcomes of biotransformation simulation studies, interstudy variabilities can also be caused by differences in the fractions of compound mass sorbed to sediment and therefore not available for biotransformation. The fact that compromised bioavailability due to sorption may be a key factor explaining the differences in the extent of biotransformation observed in standard OECD 308 studies was previously shown for different homologues of linear alkylbenzenesulfonates. ${ }^{50}$ The TOC content of the sediment employed in the here considered standard OECD 308 studies varied from 0.3 to $5.4 \%$, depending on compound and study. Strikingly, the difference in TOC content was much greater between the sediments employed in the modified OECD 308-type studies, i.e., 0.7 and $10 \%$ TOC in Rhine and CMP sediment, respectively; however, this $>10$-fold difference in TOC did not result in similar or 
even larger interstudy variabilities in $\mathrm{DT}_{50, \mathrm{TS}}$. After $54-60$ days of experiment, accumulation in the sediment of $>70 \%$ of the initial compound mass was observed for 3 of the 19 compounds compared (i.e., atazanavir, aliskiren, and azoxystrobin) in the case of modified OECD 308-type experiments, but for more than half of the test compounds in the case of standard OECD 308 studies. These observations suggest that, due to the lower sediment-water ratio, larger portions of compound mass are present in the water phase of modified OECD 308-type studies and, hence, bioavailable. As a consequence, differences in sediment TOC content less strongly affected observed $\mathrm{DT}_{50, \mathrm{Ts}}$ values in modified OECD 308-type studies and contact between compounds and sediment appeared to have resulted more often in transformation than sorption compared to the standard OECD 308 setup.

In addition to increased bioavailability of test compounds, aeration of the water column may also contribute to the enhanced biotransformation in modified OECD 308-type studies by increasing the depth of the oxic zone in the sediment. Indeed, Shrestha et al. ${ }^{8}$ showed that only the upper $\sim 1.5 \mathrm{~mm}$ of the sediment layer was aerobic in standard OECD 308 studies, while oxygen appeared to reach deeper sediment layers in aerated modified OECD 308-type studies. Since the majority of our test compounds are expected or known to undergo oxidative initial biotransformation reactions, their biotransformation can indeed be hypothesized, in line with the results of Shrestha et al., ${ }^{8}$ to be significantly enhanced in aerated modified OECD 308-type systems.

A further difference between our biotransformation experiments and standard OECD 308 studies was the fact that we added the test compounds in mixture and at an environmentally relevant concentration (i.e., $1 \mu \mathrm{g} \mathrm{L}^{-1}$ ) to the experimental vessels of modified OECD 308-type studies, while standard OECD 308 studies are commonly conducted with a single substance spiked at a higher concentration (i.e., up to $\mathrm{mg} \mathrm{L}^{-1}$ range). ${ }^{8,13,20,22}$ So far, there is no experimental evidence that spiking test compounds to OECD test systems in low concentration mixtures would alter their biotransformation kinetics. ${ }^{51}$ Yet, the concentration levels at which biotransformation tests are performed have been shown to influence transformation kinetics. For example, Hammershøj et al. ${ }^{51}$ showed that a gradual increase of initial compound concentration in OECD 309 pelagic tests inhibits biotransformation of carbohydrates. Likewise, $\mathrm{Li}$ and McLachlan ${ }^{37}$ and Coll et al. ${ }^{13}$ reported shorter half-lives at lower test concentrations for several pharmaceuticals and food additives, including gabapentin in pelagic tests and acesulfame, carbamazepine, and diclofenac in standard OECD 308 tests. Yet, pelagic tests with acesulfame, atenolol, and metoprolol indicated a more rapid compound dissipation from experimental vessels operated at higher concentration levels. ${ }^{37}$ Hence, there is still a lack of understanding how outcomes of biotransformation simulation studies are affected by different test concentrations. Still, with regard to predicting a compound's behavior in the aquatic environment based on laboratory experiments, it appears reasonable to apply the test compounds at levels close to their concentrations commonly measured in surface waters, as we attempted to do by conducting modified OECD 308-type studies in the microgram per liter to nanogram per liter range.

Comparison of DT $_{50, \text { Ts }}$ in OECD 308 and OECD 309Type Water-Sediment Studies. Figure 1 further shows
$\mathrm{DT}_{50, \mathrm{TS}}$ values derived from dissipation kinetics in suspension tests containing 1 and $10 \mathrm{~g}$ solids $\mathrm{L}^{-1}$ presented by Seller et al. ${ }^{5}$ In the case of suspension tests, Figure 1 does not only show differences between different studies but also intrastudy variabilities, i.e., variabilities observed between experimental replicates, which were most significant in R1-Spring. Even though $\mathrm{DT}_{50, \mathrm{TS}}$ values from suspension tests varied significantly and ranged from $\sim 1$ to $>100$ days, they generally indicate faster compound dissipation from suspension test systems than from standard OECD 308 systems.

$\mathrm{DT}_{50, \mathrm{TS}}$ values derived from modified OECD 308-type systems were in the same range as the variable $\mathrm{DT}_{50, \mathrm{TS}}$ values derived from suspension tests. Only two compounds, i.e., citalopram and sitagliptin, dissipated significantly slower from modified OECD 308-type systems than from suspension test systems. Both compounds accumulated in the bed sediment of modified OECD 308-type studies with $>70 \%$ of the initial compound mass being detected in the sediment layer at the end of the experiments. Even though biotransformation pathways have been suggested for both compounds, ${ }^{52,53}$ their bioavailability appears to be significantly reduced in the presence of an increased amount of sediment.

Generally, most similar $\mathrm{DT}_{50, \mathrm{TS}}$ values, regardless of the considered biotransformation test system, were derived for rapidly dissipating compounds, i.e., atenolol, bezafibrate, fenoxycarb, and trimethoprim. Despite their different sorption behavior in abiotic sorption control experiments (i.e., sorption to bed sediment in case of fenoxycarb, trimethoprim, and atenolol, Table SI6), they rapidly dissipated from all test systems since their removal from the water phase via biotransformation was faster than the establishment of sorption equilibrium with the sediment layer (Figure SI4). Further, $\mathrm{DT}_{50, \mathrm{TS}}$ values were similar in all test systems for compounds for which removal was dominated by abiotic transformation, i.e., irbesartan and hydrochlorothiazide ${ }^{37,54}$ (Table SI5). For the majority of test compounds, however, the outcomes of different biotransformation simulation studies varied greatly, resulting in differences between $\mathrm{DT}_{50, \mathrm{TS}}$ values of several orders of magnitude. These, in turn, might lead to different persistence classifications for a given compound, depending on the considered OECD study, or even depending on the experimental replicate within the same study. In this context, it is important to note that least intra- and interstudy variabilities were generally observed in modified OECD 308-type studies. Microbial Community Dynamics and Their Influence on Biotransformation of Chemicals

Previous studies have associated increased and more uniform biotransformation of micropollutants in different environmental compartments with increased cell density and diversity of microbial communities. ${ }^{5,13,23,26,43}$ Here, we explore dynamic changes in cell type abundance based on FCM data and discuss potential linkages to the compounds' variable biotransformation behavior in different OECD 308/309-type studies.

Variabilities in Bacterial Cell Densities. Inter- and intrastudy variabilities in biotransformation kinetics suggest that certain compounds can only be transformed by enzymes less widespread or only expressed under specific conditions. Such rare enzymes have a higher probability of occurrence at higher inoculum concentrations of a diverse bacterial community. $^{24,55-57}$ Hence, biotransformation of chemicals has been observed to be most robust in laboratory systems employing rather high bacterial cell densities, i.e., at the upper 


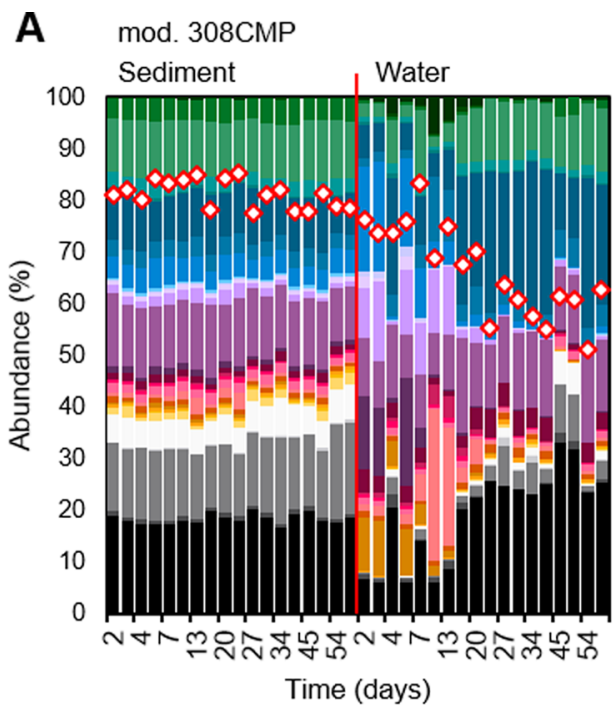

mod. 308Rhine
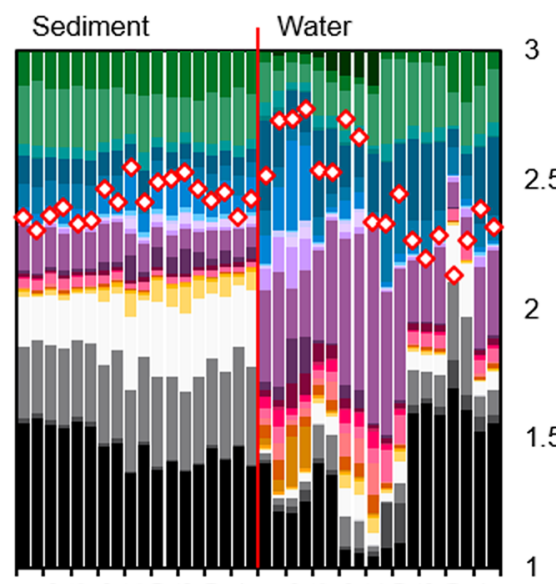

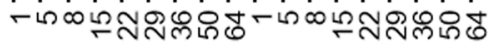

Time (days)
B $1 \mathrm{~g}$ solids $\mathrm{L}^{-1}$

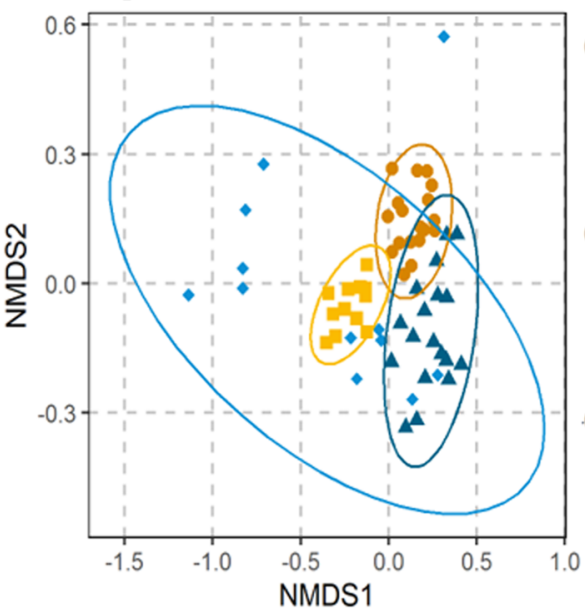

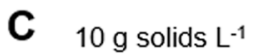

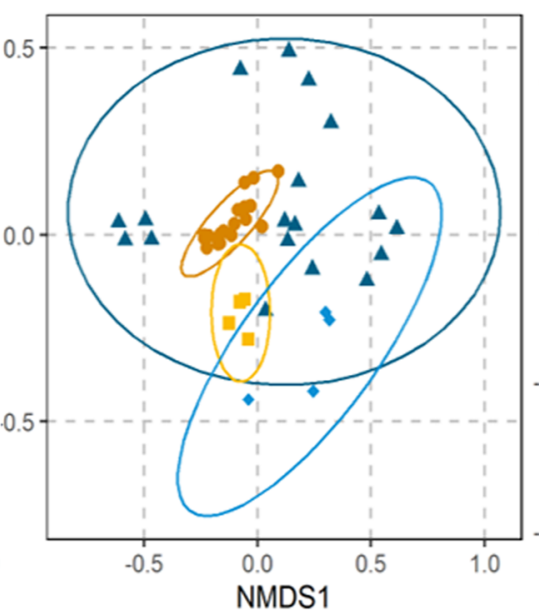

D mod. 308 studies

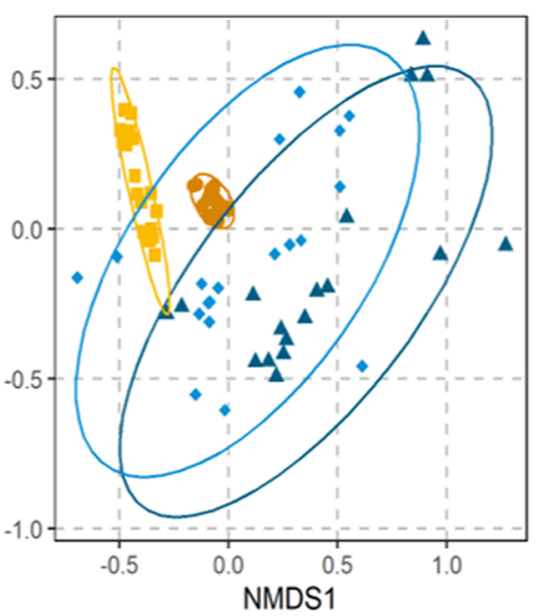

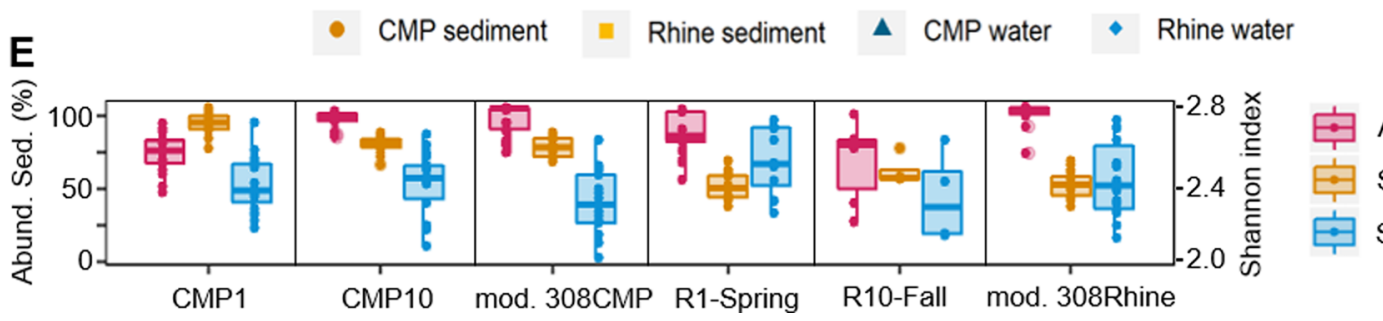

Abund. Sed.

SI Sediment

SI Water

Figure 2. Cell type composition and diversity of microbial test communities in water-sediment systems. (A) Relative abundance of cell types differing in size and shape in sediment and water samples from experimental vessel sacrificed throughout the modified OECD 308-type studies. Each sample's diversity is quantified by its respective Shannon index (red $\diamond)$. NMDS plots (B) $-(\mathrm{D})$ show dissimilarities between cell type abundances in sediment and water samples during $1 \mathrm{~g}$ solids $\mathrm{L}^{-1}$ suspension tests, $10 \mathrm{~g}$ solids $\mathrm{L}^{-1}$ suspension tests, and modified OECD 308 -type studies with their $95 \%$ confidence intervals, respectively. In all cases, stress values were $<0.2$. Box plot (E) shows median, 25 th, and 75 th percentiles of cell abundance in the sediment compartment of experimental vessels in percent (Abund. Sed.) as well as median, 25th, and 75th percentiles of Shannon indices (SI) calculated for water and sediment samples from the different biotransformation studies.

limit of what is commonly observed in the aquatic environment (i.e., $10^{6}-10^{7}$ cells $\mathrm{mL}^{-1}$ ). ${ }^{5,55,58}$ During our modified OECD 308-type experiments, the average cell counts in the experimental vessels of the Rhine and CMP studies were $4 \times$ $10^{10}$ and $1.4 \times 10^{11}$ cells, respectively. As shown in Figure $2 \mathrm{E}$, $>90 \%$ of the cells were associated with the sediment layer, which translates to cell densities of $3.8 \times 10^{8}$ and $4.3 \times 10^{9}$ cells $\mathrm{g}_{\text {dry weight }}{ }^{-1}$ in the sediment and $2.3 \times 10^{6}$ and $1.4 \times 10^{7}$ cells $\mathrm{mL}^{-1}$ in the water phase of Rhine and CMP studies, respectively. Cell densities in sediment and water phase were thus within the environmentally relevant range, however, at its upper limit in case of CMP experiments. ${ }^{16-19}$

Further, data presented by Seller et al. ${ }^{5}$ on the differences in compound removal during suspension tests suggest that intrastudy variabilities in biotransformation kinetics may coincide with variations in bacterial cell densities. More precisely, compound removal appeared to be more variable when bacterial cell densities varied more strongly between replicates and over time. Interestingly, the variation in bacterial cell densities in water-sediment test systems is generally lower 
when more cells are associated with sediment. Consistently, during modified OECD 308-type studies, i.e., studies conducted in experimental vessels containing inocula with cell densities within the environmentally relevant range and with $>90 \%$ of the cells associated with the sediment layer, biotransformation reactions were triggered for most of our test compounds. Moreover, parent compound concentrations measured in duplicate samples sacrificed at each sampling time point were in good agreement, with an average difference in the water phase and in the sediment layer of only $4 \%$ and $3 \%$ of the initial spike concentration, respectively (Figure SI4). Samples sacrificed at different time points followed consistent time trends, further supporting the notion that different test vessels behaved very consistently in modified OECD 308-type studies.

Cell Type Diversity and Community Dynamics. We deduced compositional differences and temporal changes of the microbial communities in OECD 309-type suspension tests and modified OECD 308-type studies from multidimensional flow cytometry data deconvoluted into 32 predefined classes by the machine-learning cell type assignment pipeline CellCognize. $^{28}$ Figures $2 \mathrm{~A}$ and SI7 show the deconvoluted cell type composition of sediment and water communities in replicates sampled throughout modified OECD 308-type studies and suspension tests. Generally, both Rhine and CMP microbial communities were dominated, i.e., with an average abundance $>10 \%$, by cell types similar in size and shape to the Caulobacter crescentus standard, which represents a species widely distributed in oligotrophic natural freshwater bodies, ${ }^{59}$ as well as by rod-shaped bacteria of small cell volume (i.e., B02, $\sim 0.12 \mu \mathrm{m}^{3}$ ). As expected for water-sediment systems, $^{13,49,60}$ all other cell types with an abundance > $1 \%$ could be linked to the optical characteristics of Proteobacteria (i.e., CCR, PVR, DH_STAT_LB, and PPT), Actinobacteria (i.e., ACH), and Firmicutes (i.e., BST and LCC) phyla.

Still, nonmetric multidimensional scaling (NMDS, Figure $2 \mathrm{~B}-\mathrm{D})$ of the relative attributed class abundances showed that the composition of the considered test communities differed depending on the origin of the inocula. NMDS further revealed that cell type compositions varied significantly between communities sampled from the water or sediment compartment (adonis $R^{2} \sim 0.4, p$-value $=0.001$ for each NMDS graph in Figure 2). In modified OECD 308-type studies, six CellCognize classes were predominantly detected in the sediment layers of Rhine and CMP systems (paired $t$-test between water and sediment samples $p$-value $<0.05$, Figure SI9). Those six classes included the three spherical-shaped bead standards with the highest cell volume and biomass (i.e., cell volume of 7-53 $\mu \mathrm{m}^{3}$, biomass of $1159-6612 \mathrm{fg} \mathrm{C}$ ), which were also predominantly assigned to cells associated with the suspended solids in suspension tests, i.e., B10, B15, and B6 (Figures SI10 and SI11). Higher TOC and nutrient availability in the sediment, especially in the case of CMP sediment, compared to the water phase may have caused this accumulation of cells with increased size in the sediment layer. In contrast, cells with a biomass $>10$ times lower than B6 standard beads (i.e., $\leq 126 \mathrm{fg} \mathrm{C}$ ) appeared predominantly in the water phase of modified OECD 308-type studies; their optical characteristics were similar to those of Sphingomonas wittichii and Caulobacter crescentus, two species previously isolated from oligotrophic aquatic environments. ${ }^{59,61}$

Figure $2 \mathrm{~B}-\mathrm{D}$ clearly shows that the cell type composition of the sediment-associated communities was rather stable between experimental replicates and throughout the respective experiments, i.e., $>54$ days. Interestingly, this finding was valid between the different study types, regardless of whether the sediment was kept in suspension or formed a stagnant layer at the bottom of the experimental vessels. In contrast, the communities' cell type composition in the water phases varied significantly between experimental replicates and studies, seemingly undergoing dynamic changes over the time course of the experiments. When comparing cell type diversities in the sediment and water compartments, Shannon indices indicated that diversities in the sediment were generally higher and less variable between experimental replicates and between Rhine and CMP studies, respectively (Figure $2 \mathrm{E}$ ). In the water phase, cell type diversities were lower with generally greater variation between experimental replicates and over time. Therefore, with regard to chemical biotransformation in simulation studies, we hypothesize that aquatic biotransformation can be most robustly studied in test systems providing a sufficient amount of sediment-borne biomass with high diversity that is representative for a stable community. Consistently, our results indicated more rapid and uniform biotransformation of chemicals in modified OECD 308-type test systems employing an increased amount of sediment content compared to suspension tests.

When comparing cell type composition in water and sediment samples from the Rhine to inocula sampled from $\mathrm{CMP}$, relative abundances of several cell types in CMP tests were increased compared to those in Rhine tests. These cell types included Acinetobacter, Arthrobacter, or Bacillus genera of CellCognize standards. Accordingly, Shannon indices of cell type diversities were also higher in studies employing inocula sourced from CMP than in studies employing Rhine inocula ( $t$-test $p$-value $=0.004$, Figure SI8). Lower cell type diversities in Rhine inocula may have resulted from the impact of effluent of WWTPs located along the Rhine river, as suggested in previous studies. ${ }^{49}$ However, while this indicates that the microbial community sourced from the Rhine was impacted by discharge of WWTPs, it remains unclear how this affects the community's capacity for biotransformation in laboratory studies. An increased biotransformation capacity due to preexposure of the native microbial community to micropollutants and/or the presence of competent degraders washed out of WWTPs and transported into the Rhine may compensate for the Rhine inocula's lower cell densities and diversities. At last, compound removal from modified OECD 308-type studies in CMP or Rhine inocula was similar for the majority of test compounds.

\section{Relevance and Implications for Persistence Assessment}

Our results highlight the potential advantages of studying aerobic biotransformation of pharmaceuticals, pesticides, or artificial sweeteners in modified OECD 308-type systems. Compared to OECD 309 studies, modified OECD 308-type studies showed improved observation of biotransformation and little intrastudy variability due to the presence of a sufficiently large, diverse, and stable microbial community in the bulk sediment. This also resulted in dissipation kinetics consistent with a first-order decay for the majority of compounds studied.

Outcomes of standard OECD 308 studies are often difficult to interpret as compound mass distribution can excessively shift into the sediment layer where mixed redox conditions prevail. $^{12}$ In contrast, interpretation of the outcomes of modified OECD 308-type studies is more straightforward as 
the sediment layer is thinner and mostly aerobic, and, as a consequence, dissipation from the modified test system can be assumed to be primarily due to aerobic biotransformation (or in some cases abiotic transformation) of the dissolved compound fraction in the system. Furthermore, reduced interstudy variabilities observed between $\mathrm{DT}_{50, \mathrm{Ts}}$ values derived from the modified OECD 308-type studies for the majority of compounds indicate that study outcomes are less sensitive toward differing sediment and inoculum properties, as well as toward strong confounding effects from bioavailability differences as observed in standard OECD 308 studies.

In today's standard procedures for regulatory persistence assessment, half-lives derived from biotransformation simulation studies are compared against a single persistence cutoff criterion; according to $\mathrm{REACH}$, a compound is considered persistent once its laboratory-derived half-lives exceed 40 days in freshwater or 120 days in sediment. ${ }^{3}$ This approach seems questionable when biotransformation simulation studies are intrinsically prone to interstudy, or even intrastudy variabilities: a compound may pass or fail persistence assessment depending on the considered study or even depending on the considered replicate of a study. A comparison of $\mathrm{DT}_{50, \mathrm{TS}}$ values derived from modified OECD 308-type studies to a single persistence cutoff value seems more appropriate, as our data suggests that the modified test system exhibits increased reproducibility and interpretability compared to standard OECD 309 and OECD 308 studies for a wide range of compounds. Additionally, alternative data evaluation procedures might support the evaluation of variable outcomes of biotransformation simulation studies in terms of persistence. Concepts that have been developed to account for variable biotransformation simulation study outcomes include (i) benchmarking, introduced by McLachlan et al, ${ }^{4}$ where a compound's persistence is assessed based on its behavior relative to a set of benchmark chemicals, and (ii) the $k_{\text {bio }}^{\prime}$ concept of Honti et al., ${ }^{11}$ which stipulates to derive a secondorder biomass-normalized and bioavailability-corrected rate constant $\left(k_{\text {bio }}^{\prime}\right)$ which, ideally, would allow to unify observations from different water-sediment systems.

Regardless of the applied data evaluation procedure, the environmental relevance of biotransformation simulation studies is another important topic of discussion among professionals involved in chemical persistence assessment. The standard OECD 308 study has originally been designed to assess biotransformation of pesticides at their point of release, i.e., in the uppermost, at least partially aerobic sediment layer in small, shallow, stagnant, or slowly flowing water bodies, ${ }^{12}$ and might indeed reasonably represent that situation. Further, the OECD 308 laboratory system, employing a thick, mostly anaerobic sediment layer, may be appropriate to represent biotransformation of chemicals in sediments in highly depositional areas (e.g., in the final section of rivers before discharging into the oceans). In these areas, sedimentation rates are high and redox zonation in sediment is an important consideration as contaminants are buried and hence "escape" the aerobic zone relatively quickly. However, all of the here considered substances are also frequently detected in the water column of streams and rivers. ${ }^{39}$ Therefore, we argue that their persistence should also be assessed in laboratory test systems suitable to represent fully mixed aerobic water bodies, and that modified OECD 308-type studies mimic such a situation more closely by increased aeration and a lower sediment-water ratio, shifting the compound mass in the experimental vessels more toward the water column. In that context, it is important to note that OECD 309 studies were originally developed to simulate a compound's biotransformation in the water column of natural water bodies. However, while OECD 309 studies may indeed reasonably well represent compound behavior in a deep lake, they likely are not suitable to represent river systems as they neglect hydraulic and microbial interactions between the water body and sediment layer resulting, among others, in cell densities lower than commonly observed in rivers. ${ }^{16,19}$ Overall, we hence suggest that modified OECD 308-type studies can deliver information well suited to consider a chemical's potential for aerobic biotransformation in the aquatic environment, especially in rivers, in regulatory persistence and exposure assessment.

Complementarily, based on the results of our biological analysis, we propose that FCM measurements combined with suitable data processing pipelines could represent a rapid, inexpensive, and robust analytical method that may add valuable information to the parameters currently required to be reported when performing regulatory persistence assessment. We showed how simple and sensitive measurements of phenotypic attributes of bacterial cells in the microbial communities employed during biotransformation simulation studies via FCM can provide a rapid first assessment of microbial diversity dynamics, which helps to understand different patterns in compound removal via biotransformation from different experimental vessels. While analyzing the microbial cells' FCM fingerprints cannot provide the same quality and resolution of data as, e.g., 16S rRNA amplicon sequencing-based approaches, comparison of diversity indicators derived from FCM fingerprints provided very valuable insights into differences between the test systems and aligned nicely with observations of previous research on the abundance of different species under different environmental conditions, e.g., in oligotrophic surface waters impacted by WWTP effluent. As the OECD 308 guideline does not require a detailed assessment of the employed microbial communities, ${ }^{9}$ to date, little is known about the abundance and evolution of different species during such long-duration regulatory biotransformation simulation studies. To the best of our knowledge, only one study previously analyzed microbial community composition in different standard OECD 308 experiments by means of $16 \mathrm{~S}$ rRNA sequencing, however, only at one time point after 40 days of experiments. ${ }^{13}$ Therefore, our here presented data on cell type composition in both water and sediment allows, for the first time, the study of the dynamic behavior of microbial test communities throughout different biotransformation simulation studies.

\section{ASSOCIATED CONTENT}

\section{Supporting Information}

The Supporting Information is available free of charge at https://pubs.acs.org/doi/10.1021/acsenvironau.1c00006.

Supporting information contains complementary experimental methods (including chemical and biological analysis) and data evaluation procedures, as well as graphs and tables containing complementary results (PDF) 


\section{AUTHOR INFORMATION}

\section{Corresponding Author}

Kathrin Fenner - Eawag, Swiss Federal Institute of Aquatic Science and Technology, 8600 Dübendorf, Switzerland; Department of Chemistry, University of Zürich, 8057 Zürich, Switzerland; 이이.org/0000-0001-6068-8220; Email: kathrin.fenner@eawag.ch

\section{Authors}

Carolin Seller - Eawag, Swiss Federal Institute of Aquatic Science and Technology, 8600 Dübendorf, Switzerland; Department of Chemistry, University of Zürich, 8057 Zürich, Switzerland

Birge D. Özel Duygan - Eawag, Swiss Federal Institute of Aquatic Science and Technology, 8600 Dübendorf, Switzerland; Institute of Microbiology, CHUV, 1011 Lausanne, Switzerland; Department of Fundamental Microbiology, University of Lausanne, 1015 Lausanne, Switzerland

Mark Honti - MTA-BME Water Research Group, 111 Budapest, Hungary

Complete contact information is available at:

https://pubs.acs.org/10.1021/acsenvironau.1c00006

\section{Notes}

The authors declare no competing financial interest.

\section{ACKNOWLEDGMENTS}

We thank the German Federal Ministry for the Environment, Nature Conservation and Nuclear Safety for funding (PIdent2, FKZ 371765409 0). Special thanks go to Silvia Berkner and Janina Wöltjen for contributing valuable guidance and insights on regulatory processes during the project.

\section{REFERENCES}

(1) Cousins, I. T.; Ng, C. A.; Wang, Z.; Scheringer, M. Why is high persistence alone a major cause of concern? Environmental Science: Processes \& Impacts 2019, 21 (5), 781-792.

(2) Boethling, R.; Fenner, K.; Howard, P.; Klečka, G.; Madsen, T.; Snape, J. R.; Whelan, M. J. Environmental Persistence of Organic Pollutants: Guidance for Development and Review of POP Risk Profiles. Integr. Environ. Assess. Manage. 2009, 5 (4), 539-556.

(3) ECHA. PBT/vPvB assessment, Version. 3.0. In Guidance on Information Requirements and Chemical Safety Assessment; ECHA, 2017; Chapter R.11.

(4) McLachlan, M. S.; Zou, H.; Gouin, T. Using Benchmarking To Strengthen the Assessment of Persistence. Environ. Sci. Technol. 2017, 51 (1), 4-11.

(5) Seller, C.; Honti, M.; Singer, H.; Fenner, K. Biotransformation of Chemicals in Water-Sediment Suspensions: Influencing Factors and Implications for Persistence Assessment. Environ. Sci. Technol. Lett. 2020, 7 (11), 854-860.

(6) Poursat, B. A.; van Spanning, R. J.; de Voogt, P.; Parsons, J. R. Implications of microbial adaptation for the assessment of environmental persistence of chemicals. Crit. Rev. Environ. Sci. Technol. 2019, 49 (23), 2220-2255.

(7) François, B.; Armand, M.; Marie-José, D.; Thouand, G. From laboratory to environmental conditions: a new approach for chemical's biodegradability assessment. Environ. Sci. Pollut. Res. 2016, 23 (18), 18684-18693.

(8) Shrestha, P.; Junker, T.; Fenner, K.; Hahn, S.; Honti, M.; Bakkour, R.; Diaz, C.; Hennecke, D. Simulation Studies to Explore Biodegradation in Water-Sediment Systems: From OECD 308 to OECD 309. Environ. Sci. Technol. 2016, 50 (13), 6856-6864.
(9) OECD. Test No. 308: Aerobic and Anaerobic Transformation in Aquatic Sediment Systems. In OECD Guidelines for the Testing of Chemicals, Section 3; OCED, 2002.

(10) OECD. Test No. 309: Aerobic Mineralisation in Surface WaterSimulation Biodegradation Test. In OECD Guidelines for the Testing of Chemicals, Section 3; OCED, 2004.

(11) Honti, M.; Hahn, S.; Hennecke, D.; Junker, T.; Shrestha, P.; Fenner, K. Bridging across OECD 308 and 309 Data in Search of a Robust Biotransformation Indicator. Environ. Sci. Technol. 2016, 50 (13), 6865-6872.

(12) Honti, M.; Fenner, K. Deriving Persistence Indicators from Regulatory Water-Sediment Studies-Opportunities and Limitations in OECD 308 Data. Environ. Sci. Technol. 2015, 49 (10), 5879-5886.

(13) Coll, C.; Bier, R.; Li, Z.; Langenheder, S.; Gorokhova, E.; Sobek, A. Association between Aquatic Micropollutant Dissipation and River Sediment Bacterial Communities. Environ. Sci. Technol. 2020, 54 (22), 14380-14392.

(14) Ahtiainen, J.; Aalto, M.; Pessala, P. Biodegradation of chemicals in a standardized test and in environmental conditions. Chemosphere 2003, 51 (6), 529-537.

(15) Honti, M.; Bischoff, F.; Moser, A.; Stamm, C.; Baranya, S.; Fenner, K. Relating Degradation of Pharmaceutical Active Ingredients in a Stream Network to Degradation in Water-Sediment Simulation Tests. Water Resour. Res. 2018, 54 (11), 9207-9223.

(16) Besmer, M. D.; Weissbrodt, D. G.; Kratochvil, B. E.; Sigrist, J. A.; Weyland, M. S.; Hammes, F. The feasibility of automated online flow cytometry for in-situ monitoring of microbial dynamics in aquatic ecosystems. Front. Microbiol. 2014, 5, 265.

(17) Luo, X.; Xiang, X.; Huang, G.; Song, X.; Wang, P.; Fu, K. Bacterial Abundance and Physicochemical Characteristics of Water and Sediment Associated with Hydroelectric Dam on the Lancang River China. Int. J. Environ. Res. Public Health 2019, 16 (11), 2031.

(18) Wang, Y.; Hammes, F.; Boon, N.; Egli, T. Quantification of the Filterability of Freshwater Bacteria through $0.45,0.22$, and $0.1 \mu \mathrm{m}$ Pore Size Filters and Shape-Dependent Enrichment of Filterable Bacterial Communities. Environ. Sci. Technol. 2007, 41 (20), 70807086.

(19) Whitman, W.; Coleman, D.; Wiebe, W. J. Prokaryotes: the unseen majority. Proc Nat Acad Sci USA. Proc. Natl. Acad. Sci. U. S. A 1998, 95, 6578-83.

(20) Radke, M.; Maier, M. P. Lessons learned from water/sedimenttesting of pharmaceuticals. Water Res. 2014, 55, 63-73.

(21) Ericson, J. F.; Smith, R. M.; Roberts, G.; Hannah, B.; Hoeger, B.; Ryan, J. Experiences with the OECD 308 transformation test: a human pharmaceutical perspective. Integr. Environ. Assess. Manage. 2014, 10 (1), 114-24.

(22) Ericson, J. F. An Evaluation of the OECD 308 Water/Sediment Systems for Investigating the Biodegradation of Pharmaceuticals. Environ. Sci. Technol. 2007, 41 (16), 5803-5811.

(23) Stravs, M. A.; Pomati, F.; Hollender, J. Biodiversity Drives Micropollutant Biotransformation in Freshwater Phytoplankton Assemblages. Environ. Sci. Technol. 2019, 53 (8), 4265-4273.

(24) Johnson, D. R.; Helbling, D. E.; Lee, T. K.; Park, J.; Fenner, K.; Kohler, H. P. E.; Ackermann, M. Association of Biodiversity with the Rates of Micropollutant Biotransformations among Full-Scale Wastewater Treatment Plant Communities. Appl. Environ. Microbiol. 2015, 81 (2), 666-675.

(25) Posselt, M.; Mechelke, J.; Rutere, C.; Coll, C.; Jaeger, A.; Raza, M.; Meinikmann, K.; Krause, S.; Sobek, A.; Lewandowski, J.; Horn, M. A.; Hollender, J.; Benskin, J. P. Bacterial Diversity Controls Transformation of Wastewater-Derived Organic Contaminants in River-Simulating Flumes. Environ. Sci. Technol. 2020, 54 (9), 54675479.

(26) Ott, A.; Martin, T. J.; Snape, J. R.; Davenport, R. J. Increased cell numbers improve marine biodegradation tests for persistence assessment. Sci. Total Environ. 2020, 706, 135621.

(27) Props, R.; Monsieurs, P.; Mysara, M.; Clement, L.; Boon, N. Measuring the biodiversity of microbial communities by flow cytometry. Methods Ecol. Evol. 2016, 7 (11), 1376-1385. 
(28) Özel Duygan, B. D.; Hadadi, N.; Babu, A. F.; Seyfried, M.; van der Meer, J. R. Rapid detection of microbiota cell type diversity using machine-learned classification of flow cytometry data. Commun. Biol. 2020, 3 (1), 379.

(29) van Dorst, J.; Bissett, A.; Palmer, A. S.; Brown, M.; Snape, I.; Stark, J. S.; Raymond, B.; McKinlay, J.; Ji, M.; Winsley, T.; Ferrari, B. C. Community fingerprinting in a sequencing world. FEMS Microbiol. Ecol. 2014, 89 (2), 316-30.

(30) Zuñiga, C.; Zaramela, L.; Zengler, K. Elucidation of complexity and prediction of interactions in microbial communities. Microb. Biotechnol. 2017, 10 (6), 1500-1522.

(31) Boddy, L.; Morris, C. W.; Wilkins, M. F.; Al-Haddad, L.; Tarran, G. A.; Jonker, R. R.; Burkill, P. H. Identification of 72 phytoplankon species by radial basis function neural network analysis of flow cytometric data. Mar. Ecol.: Prog. Ser. 2000, 195, 47-59.

(32) Buysschaert, B.; Kerckhof, F. M.; Vandamme, P.; De Baets, B.; Boon, N. Flow cytometric fingerprinting for microbial strain discrimination and physiological characterization. Cytometry, Part A 2018, 93 (2), 201-212.

(33) Neumann, M.; Schliebner, I. Protecting the sources of our drinking water: The criteria for identifying Persistent, Mobile, and Toxic (PMT) substances and very Persistent, and very Mobile ( $v P v M)$ substances under the EU chemical legislation REACH; Umweltbundesamt, 2019; UBA Texte 127/2019.

(34) Anliker, S.; Loos, M.; Comte, R.; Ruff, M.; Fenner, K.; Singer, $\mathrm{H}$. Assessing Emissions from Pharmaceutical Manufacturing Based on Temporal High-Resolution Mass Spectrometry Data. Environ. Sci. Technol. 2020, 54 (7), 4110-4120.

(35) Singer, H.; Jaus, S.; Hanke, I.; Lück, A.; Hollender, J.; Alder, A. C. Determination of biocides and pesticides by on-line solid phase extraction coupled with mass spectrometry and their behaviour in wastewater and surface water. Environ. Pollut. 2010, 158 (10), 30543064.

(36) Singer, H. P.; Wössner, A. E.; McArdell, C. S.; Fenner, K. Rapid Screening for Exposure to "Non-Target" Pharmaceuticals from Wastewater Effluents by Combining HRMS-Based Suspect Screening and Exposure Modeling. Environ. Sci. Technol. 2016, 50 (13), 66986707.

(37) Li, Z.; McLachlan, M. S. Biodegradation of Chemicals in Unspiked Surface Waters Downstream of Wastewater Treatment Plants. Environ. Sci. Technol. 2019, 53 (4), 1884-1892.

(38) Li, Z.; Kaserzon, S. L.; Plassmann, M. M.; Sobek, A.; Ramos, M. J. G.; Radke, M. A strategic screening approach to identify transformation products of organic micropollutants formed in natural waters. Environ. Sci.: Processes Impacts 2017, 19 (4), 488-498.

(39) Ruff, M.; Mueller, M. S.; Loos, M.; Singer, H. P. Quantitative target and systematic non-target analysis of polar organic micropollutants along the river Rhine using high-resolution massspectrometry-Identification of unknown sources and compounds. Water Res. 2015, 87, 145-154.

(40) Loeffler, D.; Hatz, A.; Albrecht, D.; Fligg, M.; Hogeback, J.; Ternes, T. A. Determination of non-extractable residues in soils: Towards a standardised approach. Environ. Pollut. 2020, 259, 113826.

(41) Chiaia-Hernandez, A. C.; Krauss, M.; Hollender, J. Screening of Lake Sediments for Emerging Contaminants by Liquid Chromatography Atmospheric Pressure Photoionization and Electrospray Ionization Coupled to High Resolution Mass Spectrometry. Environ. Sci. Technol. 2013, 47 (2), 976-986.

(42) FOCUS. Guidance Document on Estimating Persistence and Degradation Kinetics from Environmental Fate Studies on Pesticides in EU Registration; 2006; Report of the FOCUS Work Group on Degradation Kinetics, EC Document Reference Sanco/10058/2005 version $2.0,434 \mathrm{pp}$.

(43) Achermann, S.; Falås, P.; Joss, A.; Mansfeldt, C. B.; Men, Y.; Vogler, B.; Fenner, K. Trends in Micropollutant Biotransformation along a Solids Retention Time Gradient. Environ. Sci. Technol. 2018, 52 (20), 11601-11611.

(44) Bourgin, M.; Beck, B.; Boehler, M.; Borowska, E.; Fleiner, J.; Salhi, E.; Teichler, R.; von Gunten, U.; Siegrist, H.; McArdell, C. S.
Evaluation of a full-scale wastewater treatment plant upgraded with ozonation and biological post-treatments: Abatement of micropollutants, formation of transformation products and oxidation byproducts. Water Res. 2018, 129, 486-498.

(45) Abafe, O. A.; Späth, J.; Fick, J.; Jansson, S.; Buckley, C.; Stark, A.; Pietruschka, B.; Martincigh, B. S. LC-MS/MS determination of antiretroviral drugs in influents and effluents from wastewater treatment plants in KwaZulu-Natal, South Africa. Chemosphere 2018, 200, 660-670.

(46) Kahl, S.; Kleinsteuber, S.; Nivala, J.; van Afferden, M.; Reemtsma, T. Emerging Biodegradation of the Previously Persistent Artificial Sweetener Acesulfame in Biological Wastewater Treatment. Environ. Sci. Technol. 2018, 52 (5), 2717-2725.

(47) Kleinsteuber, S.; Rohwerder, T.; Lohse, U.; Seiwert, B.; Reemtsma, T. Sated by a Zero-Calorie Sweetener: Wastewater Bacteria Can Feed on Acesulfame. Front. Microbiol. 2019, 10, 2606.

(48) Desiante, W. L.; Minas, N. S.; Fenner, K. Micropollutant biotransformation and bioaccumulation in natural stream biofilms. Water Res. 2021, 193, 116846.

(49) Mansfeldt, C.; Deiner, K.; Mächler, E.; Fenner, K.; Eggen, R. I. L.; Stamm, C.; Schönenberger, U.; Walser, J.-C.; Altermatt, F. Microbial community shifts in streams receiving treated wastewater effluent. Sci. Total Environ. 2020, 709, 135727.

(50) Lara-Martín, P. A.; Gómez-Parra, A.; Köchling, T.; Sanz, J. L.; Amils, R.; González-Mazo, E. Anaerobic Degradation of Linear Alkylbenzene Sulfonates in Coastal Marine Sediments. Environ. Sci. Technol. 2007, 41 (10), 3573-3579.

(51) Hammershøj, R.; Birch, H.; Redman, A. D.; Mayer, P. Mixture Effects on Biodegradation Kinetics of Hydrocarbons in Surface Water: Increasing Concentrations Inhibited Degradation whereas Multiple Substrates Did Not. Environ. Sci. Technol. 2019, 53 (6), 3087-3094.

(52) Henning, N.; Falås, P.; Castronovo, S.; Jewell, K. S.; Bester, K.; Ternes, T. A.; Wick, A. Biological transformation of fexofenadine and sitagliptin by carrier-attached biomass and suspended sludge from a hybrid moving bed biofilm reactor. Water Res. 2019, 167, 115034.

(53) Beretsou, V. G.; Psoma, A. K.; Gago-Ferrero, P.; Aalizadeh, R.; Fenner, K.; Thomaidis, N. S. Identification of biotransformation products of citalopram formed in activated sludge. Water Res. 2016, 103, 205-214.

(54) Mbah, C. Kinetics of decomposition of irbesartan in aqueous solutions determined by high performance liquid chromatography. Pharmazie 2005, 59, 920-2.

(55) Martin, T. J.; Snape, J. R.; Bartram, A.; Robson, A.; Acharya, K.; Davenport, R. J. Environmentally Relevant Inoculum Concentrations Improve the Reliability of Persistent Assessments in Biodegradation Screening Tests. Environ. Sci. Technol. 2017, 51 (5), 3065-3073.

(56) Goodhead, A. K.; Head, I. M.; Snape, J. R.; Davenport, R. J. Standard inocula preparations reduce the bacterial diversity and reliability of regulatory biodegradation tests. Environ. Sci. Pollut. Res. 2014, 21 (16), 9511-9521.

(57) Jaeger, A.; Coll, C.; Posselt, M.; Mechelke, J.; Rutere, C.; Betterle, A.; Raza, M.; Mehrtens, A.; Meinikmann, K.; Portmann, A.; Singh, T.; Blaen, P. J.; Krause, S.; Horn, M. A.; Hollender, J.; Benskin, J. P.; Sobek, A.; Lewandowski, J. Using recirculating flumes and a response surface model to investigate the role of hyporheic exchange and bacterial diversity on micropollutant half-lives. Environmental Science: Processes \& Impacts 2019, 21 (12), 2093-2108.

(58) Ott, A.; Martin, T. J.; Acharya, K.; Lyon, D. Y.; Robinson, N.; Rowles, B.; Snape, J. R.; Still, I.; Whale, G. F.; Albright, V. C.; Bäverbäck, P.; Best, N.; Commander, R.; Eickhoff, C.; Finn, S.; Hidding, B.; Maischak, H.; Sowders, K. A.; Taruki, M.; Walton, H. E.; Wennberg, A. C.; Davenport, R. J. Multi-laboratory Validation of a New Marine Biodegradation Screening Test for Chemical Persistence Assessment. Environ. Sci. Technol. 2020, 54 (7), 4210-4220.

(59) Abraham, W.-R.; Strömpl, C.; Meyer, H.; Lindholst, S.; Moore, E. R. B.; Christ, R.; Vancanneyt, M.; Tindall, B. J.; Bennasar, A.; Smit, J.; Tesar, M. Phylogeny and polyphasic taxonomy of Caulobacter species. Proposal of Maricaulis gen. nov. with Maricaulis maris (Poindexter) comb. nov. as the type species, and emended description 
of the genera Brevundimonas and Caulobacter. Int. J. Syst. Evol. Microbiol. 1999, 49 (3), 1053-1073.

(60) Drury, B.; Rosi-Marshall, E.; Kelly, J. J. Wastewater Treatment Effluent Reduces the Abundance and Diversity of Benthic Bacterial Communities in Urban and Suburban Rivers. Appl. Environ. Microbiol. 2013, 79 (6), 1897-1905.

(61) Yabuuchi, E.; Yamamoto, H.; Terakubo, S.; Okamura, N.; Naka, T.; Fujiwara, N.; Kobayashi, K.; Kosako, Y.; Hiraishi, A. Proposal of Sphingomonas wittichii sp. nov. for strain RW1T, known as a dibenzo-p-dioxin metabolizer. Int. J. Syst. Evol. Microbiol. 2001, 51 (2), 281-292. 